\title{
In Vitro Propagation of Arundinaria callosa Munro- an Edible Bamboo from Nodal Explants of Mature Plants
}

\author{
W. Sayanika Devi and G.J. Sharma* \\ Department of Life Sciences, Manipur University, Imphal-795003, India
}

\begin{abstract}
A procedure for in vitro propagation of Arundinaria callosa Munro has been developed. The method allows bud-break from nodal segments containing single axillary bud on Murashige and Skoog (1962) medium supplemented with different concentrations of 6- benzylaminopurine (BAP). The early bud-break was obtained in 8.9-13.3 $\mu \mathrm{M}$ BAP, within 8-15 days. The position of the node on the culm of lateral branches also affected bud-break percentage and multiplication, mid-culm nodes are the most suitable. The optimal concentration of $13.3 \mu \mathrm{M}$ BAP is found significant for shoot multiplication. Addition of $1.0 \mu \mathrm{M} 3$ - indolebutyric acid (IBA) enhances the shoot multiplication rate. In vitro rooting was induced when $15 \mu \mathrm{M}$ IBA was incorporated for three subcultures in the shoot proliferation medium, was transferred to $1 / 2$ strength MS containing $25 \mu \mathrm{M}$ IBA and $0.05 \mu \mathrm{M}$ BAP, and finally withdrawn from the rooting medium. The regenerants were successfully transplanted into a soil mixture for acclimatization before field planting.
\end{abstract}

\section{INTRODUCTION}

Arundinaria callosa Munro, is an evergreen thorny bamboo which grows abundantly in dense foggy areas of the hill peaks in Manipur (at 2,800-9,000 ft altitude) situated in the north-eastern India. The culms are $20-40 \mathrm{ft}$ high and 0.6-3 inch in diameter, upper portions are reduced in size and bent downwards, short thick conical spines present at the nodes. The young juvenile shoots are edible and regarded as one of the common vegetables of the local people. These bamboo shoots are rich sources of nutrient and other minerals [1]. Another important constituent of bamboo shoots are the phytosterols which serve as precursor to many pharmaceutically active steroids found in plants [2]. Most bamboos grow naturally in mountainous areas where neither chemical fertilizers nor pesticides are applied. Therefore, bamboo shoots provide clean vegetables without pollution. In Manipur, the fermented shoot is one of the popular indigenous food items prepared by using traditional methods. Fermented young shoots of A. callosa (locally known as 'soidon') are used in the preparation of many traditional food items. Indiscriminate exploitation of this natural resource to meet the ever increasing demand, and insufficient attempts for replenishment and cultivation have resulted in severe depletion of wild stock, resulting in critically low population levels of this bamboo species. The conventional propagation is associated with many problems such as unpredictable flowering cycle, seed remaining viable for limited period and difficult vegetative propagation [3, 4]. Hence, the present study has been undertaken to conserve the wild stocks using in vitro propagation techniques for this important edible bamboo species. This paper describes an efficient and rapid method of in vitro propagation of A. callosa from nodal explants of adult grown clump.

\footnotetext{
*Address correspondence to this author at the Department of Life Sciences, Manipur University, Imphal-795003, India; Tel: +91- 2435055/2435276; Fax: +91- 2435145; E-mail: gjs1951@ rediffmail.com
}

\section{MATERIALS AND METHODS}

Nodal segments $(1.0-1.5 \mathrm{~cm})$ with unsprouted buds of Arundinaria callosa Munro were collected from the lateral branches of young culm growing in the natural forest of Leimaram hill located in the Bishnupur District of Manipur. The lateral branches for experiments were collected at two different seasons i.e. May-July (rainy season) and September-November (after raining season). Nodal segments, containing axillary buds were washed with Exalin (Merck) and rinsed thouroughly with double-distilled water. Then, nodes containing lateral spines were removed by scraping carefully with scapel before undergoing surface sterilization. These explants were surface-sterilized with $0.1 \%$ solution of mercuric chloride $\left(\mathrm{HgCl}_{2}\right)$ for 10 mins followed by washing with autoclaved double-distilled water for 3-4 times. The sterilized nodal buds were cultured in liquid Murashige and Skoog's (MS) [5] medium supplemented with various concentrations of BAP. The $\mathrm{pH}$ of the medium was adjusted to 5.7 prior to autoclaving at $121^{\circ} \mathrm{C}$ for 15 mins. In all the cases, $\mathrm{pH}$ of the media was adjusted by using $1 \mathrm{~N} \mathrm{NaOH}$ and $1 \mathrm{~N} \mathrm{HCl}$. The plant growth regulators (PGRs) were purchased from Sigma chemical Co., USA. The proliferated axillary shoots were excised and cut into 3-5 shoot clusters and cultured in liquid MS medium supplemented with various concentrations of BAP or in combination of $13.3 \mu \mathrm{M}$ BAP with various concentrations of IBA or $\alpha$-naphthalene acetic acid (NAA). After first shoot multiplication, the shoot cultures were cut into 3 shoot clusters and transferred to liquid MS medium containing PGRs. The shoots in liquid cultures were supported by using filter paper bridges and regularly transferred to fresh medium to check the influence of phenolic exudation. The number of propagules cultured and propagules derived at the end of subculture is regarded as the rate of multiplication.

For studies on in vitro rooting, the shoots were cut into 3-4 shoot clusters and placed on $1 / 2$ strength MS medium incorporated with $15 \mu \mathrm{M}$ IBA and $13.3 \mu \mathrm{M}$ BAP for two subcultures. These shoots were then transferred to $1 / 2$ strength 
MS medium supplemented with 10-25 $\mu \mathrm{M}$ IBA before transfer to PGR-free $1 / 2$ strength MS medium for further root growth and development. After 8 weeks of culture, the number of roots per propagule and rooting percentage was recorded.

All computations were made using SPSS (Version 14, SPSS Inc. Chicago, USA). The statistical significance was calculated by one-way ANOVA followed by Tukey's comparision tests at $5 \%$ probability test.

Field transfer of in vitro rooted plantlets was carried out by transferring the plantlets to pots containing sand: soil: FYM (farm yard manure) in 1:1:1 ratio, maintained at $30 \pm 2{ }^{\circ} \mathrm{C}$ and relative humidity of $80 \pm 5 \%$. These plants were supplied with half-strength MS medium (without organics) twice a week.

\section{RESULTS}

\subsection{Culture Initiation}

Treatment with $0.1 \% \mathrm{HgCl}_{2}$ did improve the frequency of aseptic cultures without adversely affecting the overall frequency of the bud-break. Considering the incidence of browning and the frequency of bud-break, $0.1 \% \mathrm{HgCl}_{2}$ for 10 min was regarded as the best treatment to initiate aseptic cultures of nodal segments from mature plants. The explants collected during rainy season showed high rate of bacterial contamination. As a result, the percentage of in vitro bud-break was found to be low. However, the contamination rate was reduced to $30 \%$ with good response of bud-break in all the explant cultures collected after monsoon. On basal medium, the frequency of bud-break was very low. Statistical analysis showed that in the presence of BAP, there was significant increase in the percentage of bud-break (Table 1). Early bud-break response was observed in 8.9-13.3 $\mu \mathrm{M}$ BAP within 8-15 days. In all the experiments, 1-3 shoots proliferated as a result of axillary bud-break (Fig. 1a). About $62 \%$ cultures showed bud-break within 7-10 days, with over 3 shoots per explants in MS medium containing BAP at an optimum level of $13.3 \mu \mathrm{M}$ BAP. The position of the nodal buds on the culm of lateral branches did affect bud-break (Fig. 2). Nodal explants taken from the top showed low bud-break compared to the basal and mid-culm nodes of the secondary branches.

\subsection{Shoot Multiplication}

The axillary shoots produced from primary cultures of nodal segments were transferred to various shoot multiplication media (Fig. 1b). To study the effect of cytokinin, BAP was tested alone at different concentrations. The BAP treatments were carried out at six different concentrations ranging from 4.4-31.1 $\mu \mathrm{M}$ (Table 2). Of these, treatment with 13.3 $\mu \mathrm{M}$ BAP showed significant increase in shoot multiplication (Fig. 1c). Increased concentrations (22.2-31.1 $\mu \mathrm{M}$ BAP) showed steady decline in shoot multiplication rate as well as shoot length. To improve the rate of shoot multiplication, IBA or NAA, each at different concentrations (1.0, 2.0 \& 3.0) $\mu \mathrm{M}$ were added to liquid MS containing $13.3 \mu \mathrm{M}$ BAP. Of all the auxin treatments, $1.0 \mu \mathrm{M}$ IBA proved to be the most effective with respect to the rate of shoot multiplication and shoot growth (Fig. 1d). NAA proved to be inhibitory at all the concentrations used. The presence of NAA caused yellowing and browning of leaves.

\subsection{Root Induction and Plantlet Development}

The root induction experiment was done by incorporating $15 \mu \mathrm{M}$ IBA to the shoot multiplication medium. Subsequently, a cluster of 3-5 shoots (propagules) were transferred to the rooting medium. No rooting occurred when $10 \mu \mathrm{M}$ IBA was incorporated in $1 / 2$ strength MS medium (Table 3). $30-40 \%$ rooting was obtained in MS medium supplemented with $15-25 \mu \mathrm{M}$ IBA. The rooting and rooting percentage significantly increased when $0.05 \mu \mathrm{M}$ BAP was added to $10-$ $25 \mu \mathrm{M}$ IBA supplemented medium. The maximum roots per propagules and rooting percentage obtained were 3.8 and $75 \%$ respectively on $1 / 2$ strength MS liquid medium supplemented with $25 \mu \mathrm{M}$ IBA and $0.05 \mu \mathrm{M}$ BAP (Fig. 1e). The transfer of in vitro rooted shoots to PGR-free $1 / 2$ strength MS

Table 1. Effect of BAP Supplemented MS Medium on Bud-Break Percentage and Number of Shoots per Explant from Nodal Explants of Arundinaria callosa. Data Scored after 2 weeks in Culture

\begin{tabular}{|c|c|c|}
\hline BAP Concentration $(\boldsymbol{\mu M})$ & Bud-Break Frequency $(\%)$ & No. of Shoots/Explant* $^{*}$ \\
\hline \hline 0 & 34.0 & $1.0 \pm 0.3^{\mathrm{ab}}$ \\
\hline 2.2 & 52.0 & $1.6 \pm 0.4^{\mathrm{abc}}$ \\
\hline 4.4 & 60.0 & $2.4 \pm 0.7^{\mathrm{abc}}$ \\
\hline 8.9 & 66.0 & $3.0 \pm 0.6^{\mathrm{bc}}$ \\
\hline 13.2 & 62.0 & $3.4 \pm 0.2^{\mathrm{c}}$ \\
\hline 22.2 & 58.0 & $2.2 \pm 0.6^{\mathrm{abc}}$ \\
\hline 26.6 & 54.0 & $1.8 \pm 0.5^{\mathrm{abc}}$ \\
\hline 31.1 & 50.0 & $1.6 \pm 0.4^{\mathrm{abc}}$ \\
\hline 44.4 & 46.0 & \\
\hline
\end{tabular}

* Mean of 10 replicates \pm S.E.

Mean followed by the same letter did not differ significantly at $\mathrm{q}<0.05$, according to Tukey's comparision test. 

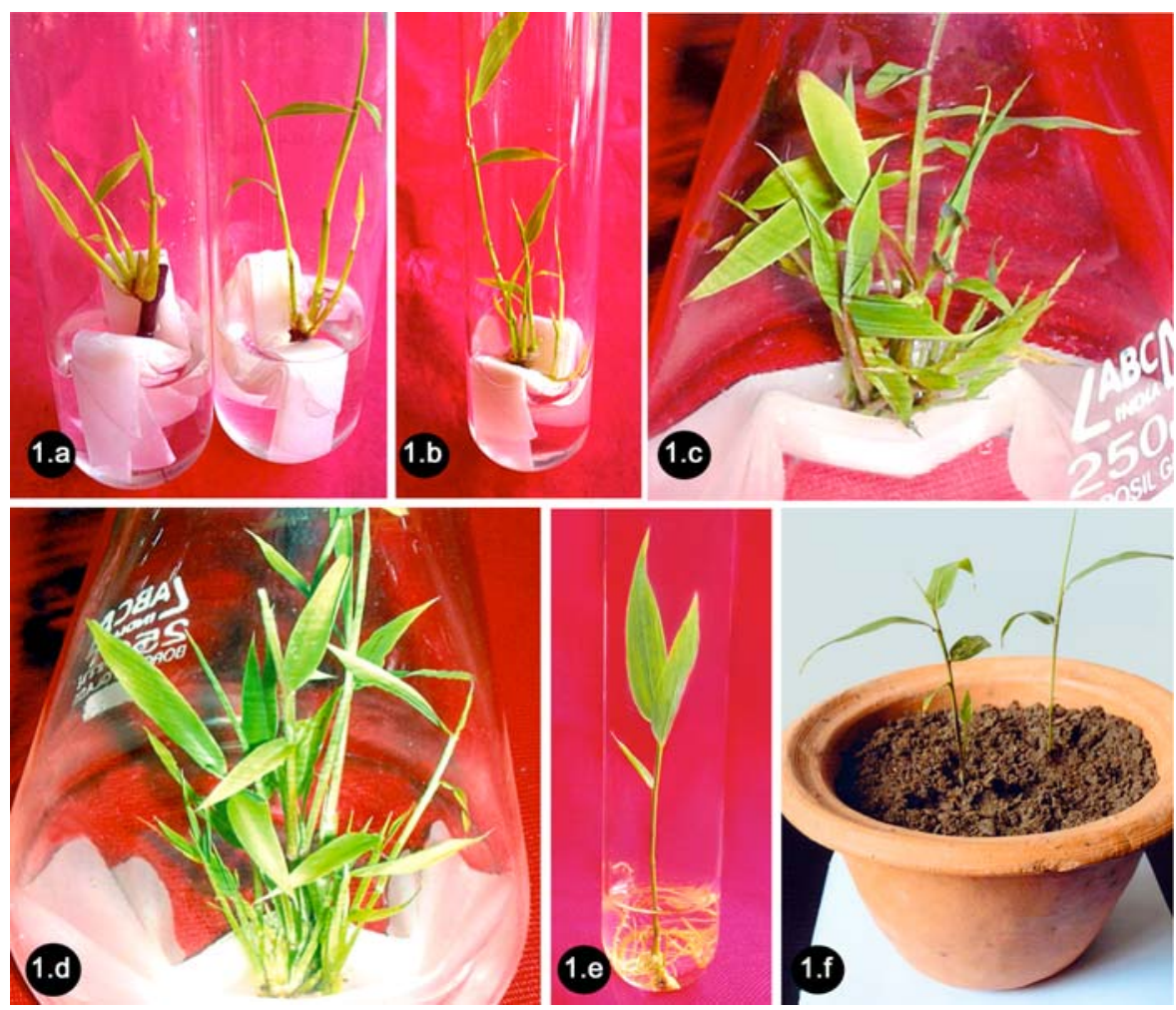

Fig. (1). Micropropagation of Arundinaria callosa (a) axillary bud-break in liquid medium (b) axillary shoot proliferation in MS medium (c) multiple shoots formation on $\mathrm{MS}+13.3 \mu \mathrm{M}$ BAP (d) multiple shoots formation on $\mathrm{MS}+1.0 \mu \mathrm{M} \mathrm{IBA}+13.3 \mu \mathrm{M} \mathrm{BAP}(\mathbf{e})$ root formation in $1 / 2 \mathrm{MS}+25 \mu \mathrm{M}$ IBA $+0.05 \mu \mathrm{M}$ BAP (f) a micropropagated plant established on soil.

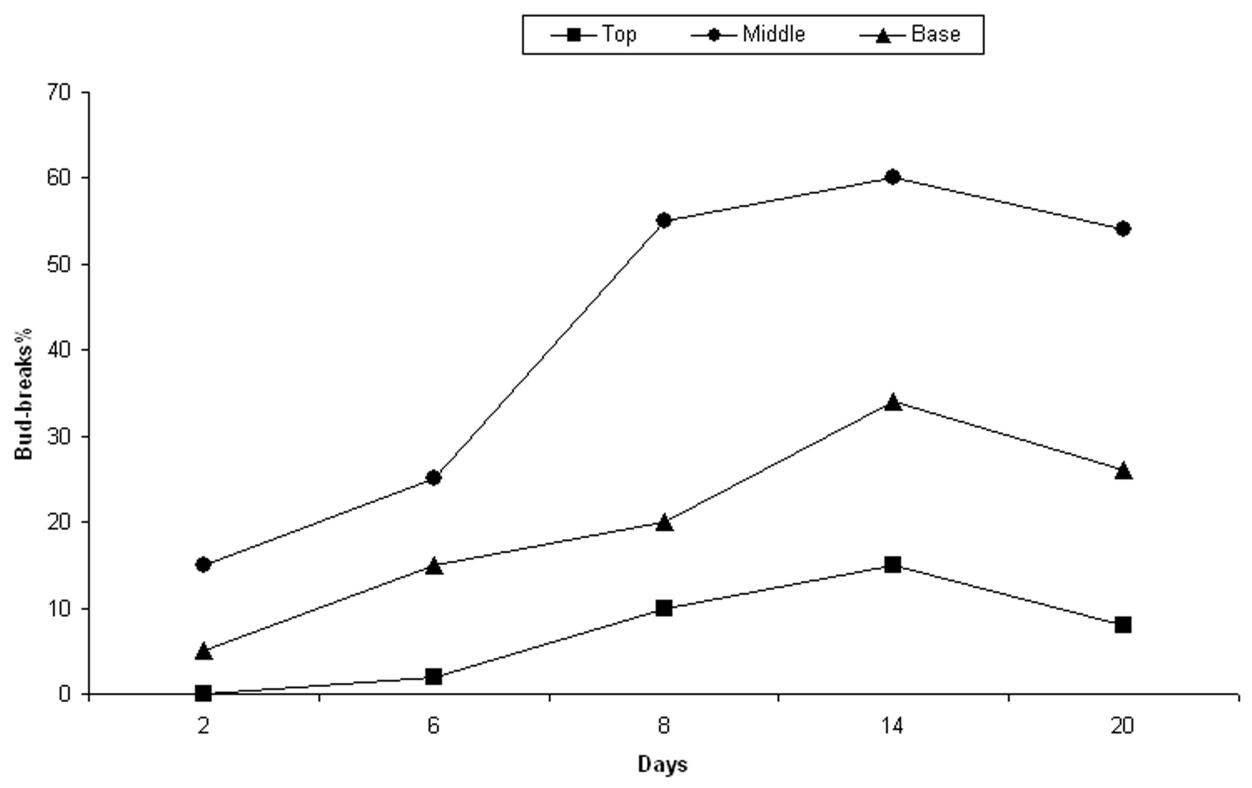

Figure2: Effect of bud-break percentage on the position of the node on the culm of lateral branches

Fig. (2). Effect of bud-break percentage on the position of the node on the culm of lateral branches.

medium produced good quality root and growth within 7-10 days. The above rooting procedure, i.e., initial exposure to IBA, subsequent transfer to medium containing IBA and BAP, and finally withdrawal of PGR from the rooting medium was found effective for overall root development. The shoots turned green and elongated after hardening. All the plants were found to be established with $60-70 \%$ survival (Fig. 1f).

\section{DISCUSSION}

Bamboo shoots are greatly demanded in the international market for their shoot-based food industry. Among the 
Table 2. Effect of Growth Regulators on Shoot Growth and Multiplication of Arundinaria callosa

\begin{tabular}{|c|c|c|c|}
\hline Growth Regulators $(\mu \mathrm{M})$ & No. of Shoot Produced* & Multiplication Rate* & Shoot Length(cm)* \\
\hline \hline 4.4 BAP & $6.3 \pm 1.8^{\mathrm{a}}$ & $1.8 \pm 0.5^{\mathrm{a}}$ & $3.7 \pm 0.5^{\mathrm{a}}$ \\
\hline 8.9 BAP & $13.0 \pm 2.2^{\mathrm{ab}}$ & $4.2 \pm 0.8^{\mathrm{ab}}$ & $3.5 \pm 0.3^{\mathrm{a}}$ \\
\hline 13.3 BAP & $15.7 \pm 0.9^{\mathrm{b}}$ & $5.2 \pm 0.3^{\mathrm{b}}$ & $3.3 \pm 0.3^{\mathrm{a}}$ \\
\hline 22.2 BAP & $15.8 \pm 1.5^{\mathrm{b}}$ & $5.0 \pm 0.5^{\mathrm{b}}$ & $3.2 \pm 0.3^{\mathrm{a}}$ \\
\hline 26.6 BAP & $11.7 \pm 1.9^{\mathrm{ab}}$ & $3.8 \pm 0.7^{\mathrm{ab}}$ & $3.1 \pm 0.3^{\mathrm{a}}$ \\
\hline 31.1 BAP & $11.5 \pm 2.0^{\mathrm{ab}}$ & $3.7 \pm 0.8^{\mathrm{ab}}$ & $3.9 \pm 0.3^{\mathrm{a}}$ \\
\hline $1.0 \mathrm{IBA}+13.3 \mathrm{BAP}$ & $16.5 \pm 0.5^{\mathrm{b}}$ & $5.2 \pm 0.2^{\mathrm{b}}$ & $3.8 \pm 0.4^{\mathrm{a}}$ \\
\hline $2.0 \mathrm{IBA}+13.3 \mathrm{BAP}$ & $15.0 \pm 1.2^{\mathrm{ab}}$ & $4.5 \pm 0.3^{\mathrm{ab}}$ & $3.6 \pm 0.4^{\mathrm{a}}$ \\
\hline $3.0 \mathrm{IBA}+13.3$ BAP & $13.2 \pm 2.1^{\mathrm{ab}}$ & $4.0 \pm 0.7^{\mathrm{ab}}$ & $3.5 \pm 0.4^{\mathrm{a}}$ \\
\hline $1.1 \mathrm{NAA}+13.3$ BAP & $12.3 \pm 1.8^{\mathrm{ab}}$ & $3.8 \pm 0.6^{\mathrm{ab}}$ & $3.5 \pm 0.2^{\mathrm{a}}$ \\
\hline $2.2 \mathrm{NAA}+13.3$ BAP & $11.2 \pm 2.0^{\mathrm{ab}}$ & $3.5 \pm 0.7^{\mathrm{ab}}$ & $2.9 \pm 0.3^{\mathrm{a}}$ \\
\hline $3.3 \mathrm{NAA}+13.3$ BAP & $8.2 \pm 1.9^{\mathrm{a}}$ & $2.3 \pm 0.7^{\mathrm{a}}$ & \\
\hline
\end{tabular}

* Mean of 10 replicates \pm S.E.

Mean followed by the same letter did not differ significantly at q $<0.05$, according to Tukey's comparision test.

Table 3. Effect of Treatments on Rooting of Arundinaria callosa on $1 / 2$ Strength MS Medium

\begin{tabular}{|c|c|c|}
\hline Treatment $(\mu \mathrm{M})$ & Average Root no* & Rooting Percentage \\
\hline \hline $10.0 \mathrm{IBA}$ & 0 & 30.0 \\
\hline $15.0 \mathrm{IBA}$ & $1.2 \pm 0.6^{\mathrm{a}}$ & 40.0 \\
\hline $25.0 \mathrm{IBA}$ & $1.4 \pm 0.2^{\mathrm{a}}$ & 55.0 \\
\hline $10.0 \mathrm{IBA}+0.05 \mathrm{BAP}$ & $1.8 \pm 0.6^{\mathrm{ab}}$ & 66.7 \\
\hline $15.0 \mathrm{IBA}+0.05 \mathrm{BAP}$ & $2.0 \pm 0.5^{\mathrm{ab}}$ & 75.0 \\
\hline $25.0 \mathrm{IBA}+0.05 \mathrm{BAP}$ & $3.8 \pm 0.6^{\mathrm{b}}$ & \\
\hline
\end{tabular}

* Mean of 10 replicates \pm S.E.

Mean followed by the same letter did not differ significantly at $q<0.05$, according to Tukey's comparision test.

north-eastern States of India, the maximum production of fresh shoots comes from Manipur with production averaging 2,188 tonnes per annum [6]. Tremendous socio-economic pressures besides jhum cultivation in the natural habitats have often compelled over-exploitation of raw bamboo resources to a critical level. Tissue culture techniques offer an effective strategy for rapid propagation and mass multiplication of edible bamboo species keeping in view of their sustainable development and utilization.

The initial aim of these experiments was to establish aseptic culture conditions under which bamboos could be propagated in vitro. The present investigation shows that explants collected during rainy season show high bacterial contamination because collection of nodal explants are possible only during the warm rainy season (May-August) when bacterial contaminations are high. On the contrary, the successful aseptic culture initiation and frequency of bud-break are achieved when explants are collected after the monsoon. Mascarenhas et al. [7] reported that microbial culture contaminants obstructed in vitro sprouting of nodes in D. strictus from adult field culms. The present work on Arundinaria callosa shows the importance of cytokinin, i.e., BAP for bud-break. This can be expected in general as cytokinin is known to overcome apical dominance resulting in the growth of axillary buds. Similar observations have been reported in Bambusa bambos [3] and Dendrocalamus strictus [8]. The relative position of the buds on the nodes also influenced the frequency of bud-break in the present experiments. Similar findings have also been reported in Dendrocalamus longispathus [9] and Bambusa vulgaris [10] that the mid-culm nodes of secondary branches are the potential explants for axillary shoot initiation. The occurrence of phenolic exudation at the cut ends of explants was the main problem faced during the present study. Due to this exudation, the explants could not survive and eventually died without giving any response. This problem was, however, overcome by proper removal of brown leaf sheaths and quick transfer to fresh medium whenever browning appeared. Researches carried out on micropropagation of bamboo showed variation in species in response to levels of BAP for shoot multiplication as in the case of Dendrocalamus longispathus [9], Dendrocalamus giganteus [11] and Bambusa bambos [3]. The present investigation shows that 13.3 $\mu \mathrm{M}$ BAP significantly induces shoot multiplication. The 
combined effect of cytokinins and auxins proves to be useful in increasing shoot multiplication. Synergistic effect of BAP and IBA shown is in agreement with the findings in Thamnocalamus spathiflorus [12]. A serious problem preventing successful micropropagation of bamboo and other woody species is their reluctance to form root $[13,14]$, and Arundinaria callosa is not an exception. The induction of rooting in many bamboo species require many additives such as coumarin, phloroglucinol and TDZ, particularly when the explant is taken from the nodal segments of adult plants [11, 15]. Saxena and Bhojwani [9] achieved $73 \%$ rooting in Dendrocalamus longipathus in a medium supplemented with coumarin along with auxins (IAA and IBA). In the present study, coumarin was not necessary for the development of roots when supplemented with IBA in the rooting medium. A three-step rooting procedure followed in the present investigation resulted in excellent rooting. The transfer of plantlets in PGR-free medium overcomes this problem, thereby giving rise to healthy growth of roots. Bag et al. [12] reported that when microshoots were transferred to PGR-free medium following initial culture in medium supplemented with IBA, $100 \%$ rooting efficiency could be achieved.

\section{CONCLUSION}

In vitro bud-break was enhanced by supplementation of BAP. MS medium with $13.3 \mu \mathrm{M}$ BAP was optimal for shoot multiplication and synergistic intereaction with $1.0 \mu \mathrm{M}$ IBA enhanced its multiplication rate. The three-steps rooting procedure increased the root number and rooting percentage. The plant survival was about $70 \%$ when acclimatization was carried out by transferring the plantlets to potting mixture. In conclusion, the present study presents a detailed protocol for successful rapid micropropagation of Arundinaria callosa, an edible bamboo from nodal explants of adult plant.

\section{ABBREVIATIONS}

$\begin{array}{lll}\text { BAP } & = & \text { 6-benzylaminopurine } \\ \text { IBA } & = & \text { indole-3-butyric acid } \\ \text { NAA } & =\alpha \text {-naphthalene acetic acid } \\ \text { PGR } & =\text { Plant growth regulator }\end{array}$

\section{REFERENCES}

[1] Bhatt BP, Singha LB, Sachan MS, Singh K. Commercial edible bamboo species of the North-Eastern Himalayan Region, India. Part II: fermented, roasted and boiled bamboo shoot sales. J Bamboo Rattan 2005; 4(1): 13-31.

[2] Srivastava RC. Bamboo, new raw material for phytosterols. Curr Sci 1990; 59: 1333-4.

[3] Arya S, Sharma S. Micropropagation technology of Bambusa bambos through shoot proliferation. Indian Forrester 1998; 124(9): 725-31.

[4] Godbole S, Sood A, Thakur R, Sharma M, Ahuja PS. Somatic embryogenesis and its conversion into plantlets in a multipurpose bamboo, Dendrocalamus hamiltonii Nees et Arn. Ex Munro. Curr Sci 2002; 83(7): 885-8.

[5] Murashige T, Skoog F. A revised medium for rapid growth and bioassays with tobacco tissue cultures. Physiol Planta 1962; 15: 473-97.

[6] Bhatt BP, Singha LB, Sachan MS, Singh K. Commercial edible bamboo species of North-Eastern Himalayan Region, India. Part I: Young shoot sales. J Bamboo Rattan 2004; 3(4): 337-64.

[7] Mascarenhas AF, Nadgir AL, Thengane SR, et al. Proceeding of the International Bamboo Workshop. In: Rao IVR, Gnanaharan R, Sastry CB, Eds. Bamboo, current research. Potential application of tissue culture for propagation of Dendrocalamus strictus. Kerala Forest Research Institute/ IDRC, India/ Canada 1988.

[8] Chowdhury P, Das M, Sikdar SR, Pal A. Influence of the physiological age and position of the nodal explants on micropropagation of field-grown Dendrocalamus strictus Nees. Plant Cell Biotech Mol Biol 2004; 5(1-2): 45-50.

[9] Saxena S, Bhojwani S. In vitro clonal multiplication of 4-year-old plants of the bamboo, Dendrocalamus longispathus Kurz. In vitro Cell Devl Biol Plant 1993; 29: 135-42.

[10] Hirimburegama K, Gamage N. Propagation of Bambusa vulgaris (yellow bamboo) through nodal bud culture. Hortic Sci 1995; 70: 469-75.

[11] Ramanayake SMSD, Yakandawala K. Micropropagation of the giant bamboo (Dendrocalamus giganteus Munro.) from nodal segments taken from field grown culms. Plant Sci 1997; 129: 21323 .

[12] Bag N, Chandra S, Palni LMS, Nandi SK. Micropropagation of Dev-ringal [Thamnocalamus spathiflorus (Trin) Munro]- a temperate bamboo and comparison between in vitro propagated plants and seedlings. Plant Sci 2000; 156: 125-35.

[13] Nemeth G. Induction of rooting, Biotechnology in Agriculture and Forestry 1, Trees 1. Berlin, Heidelberg: Springer-Verlag 1986; pp. 49-64.

[14] Gielis J, Peeters H, Gillis K, Oprins J, Debergh PC. Tissue culture strategies for genetic improvement of bamboo. Acta Hortic 2001; 552: 195-2003.

[15] Ramanayake SMSD, Meemaduma VN, Weerawardene TE. In vitro shoot proliferation and enhancement of rooting for the large-scale propagation of yellow bamboo (Bambusa vulgaris 'Striata'). Sci Hortic 2006; 110: 109-13. 